\title{
Pelatihan dan Pengembangan Sumber Daya Manusia Berbasis Integrated Bisnis Simulator (IBS) pada Guru SMK di Jakarta
}

\author{
Rutinaias Haholongan, Ridwan Maronrong, Syahrul Effendi, Krisnando
}

\author{
Fakultas Ekonomi \\ Sekolah Tinggi Ilmu Ekonomi Indonesia Jakarta \\ E-mail : rutinaias@gmail.com
}

DOI: http://dx.doi.org/10.21107/pgd.v5i1.5158

Artikel Diterima : 5 Januari 2019/ Revisi : 7 Februari 2019/Terbit : 15 April 2019

\begin{abstract}
Abstrak
Pengabdian masyarakat bertujuan untuk mendeskripsikan penerapan manajemen sumber daya manusia guru yang terfokus pada proses pelatihan dan pengembangan sumber daya manusia guru di SMK Jakarta. Kegiatan pengabdian kepada masyarakat berupa penyuluhan bagaimana peserta dapat mengembangkan keterampilan sesuai dengan perubahan teknologi, sehingga pekerjaan dapat diselesaikan lebih cepat dan efektif, Peserta dapat meningkatkan semangat kerja seluruh tenaga kerja dalam organisasi dengan komitmen organisasional yang lebih tinggi, Peserta dapat menyiapkan para karyawan yang berkompeten untuk lebih cepat masuk ke tingkat senior (promosi jabatan). Kegiatan dilakukan di sekolah tinggi ilmu ekonomi indonesi Jakarta berjalan dengan lancar dengan harapan yaitu guru - guru SMK Jakarta dapat mempraktekkan materi yang telah disampaikan. Guru - guru SMK Jakarta sadar akan pentingnya perubahan teknologi, hal ini dibuktikan dengan penyelesaian pekerjaan lebih cepat dan efisien dan semangat kerja yang tinggi.
\end{abstract}

Kata Kunci : Pelatihan, pengembangan SDM, Integrated Bisnis Simulator , Guru, SMK

\section{PENDAHULUAN}

Untuk memajukan sekolah, manajemen SDM yang terpenting adalah dari faktor tenaga pendidiknya, dengan memiliki tenaga pendidik yang kompeten dibidangnya maka akan dapat memberikan kontribusi yang bermanfaat bagi keberlangsungan/kemajuan sebuah sekolah. Mutu juga dapat dilihat bagaimana sekolah melalui guru-gurunya dapat melaksanakan tugas sebagai pendidik, pengajar, pembimbing dan pelatih sesuai dengan tuntutan kurikulum yang telah ditetapkan secara baku dalam konteks lokal maupun nasional. Mutu juga di tentukan bagaimana input, proses, output yang ada di SMK.

Guru dan karyawan merupakan salah satu komponen sumber daya manusia pendidikan yang harus dikelola dan dikembangkan terusmenerus. Hal ini dikarenakan tidak semua guru yang berada di lembaga pendidikan terlatih dengan baik dan memiliki kualifikasi yang baik (Sahertian, 2008). Potensi sumber daya guru dan karyawan itu perlu terus-menerus bertumbuh dan berkembang agar dapat melaksanakan fungsinya secara professional (Suryosubroto, 2010).

Mengingat berat dan kompleksnya membangun pendidikan, maka sangat penting untuk melakukan upaya-upaya untuk mengembangkan guru dan karyawan agar semakin profesional. Dalam kode etik guru dikatakan bahwa guru adalah seorang pendidik, jadi dia bukan sekedar sebagai pengajar. Sebagai seorang pendidik, maka keberadaan guru bukan hanya sekedar berkewajiban menyampaikan skill dan nilai (Widodo, 2015). Untuk bisa memiliki skill guru harus memerlukan latihan, pembiasaan dan pendidikan yang cukup. Itulah sebabnya, upaya pengembangan guru dan karyawan pendidikan memiliki peran yang cukup baik dalam meningkatkan kualitas pendidik dan profesionalisme pendidik. Apabila tenaga pendidik (guru) dan tenaga kependidikan (karyawan) berkualitas dan profesional, maka berkembang pula lembaga pendidikannya.

Manajemen sumber daya manusia ditujukan kepada peningkatan konstribusi yang dapat diberikan oleh para pekerja dalam organisasi ke arah pencapaian tujuan organisasi (Mangkunegara, 2013). Dibentuknya satuan organisasi yang mengelola sumber daya manusia dimaksudkan bukan sebagai tujuan, akan tetapi sebagai alat untuk meningkatkan efisiensi, efektivitas dan produktivitas kerja organisasi sebagai keseluruhan (Pidarta, 2011). Sumber 
daya manusia dipandang semakin besar peranannya bagi kesuksesan suatu organisasi. Banyak organisasi kini menyadari bahwa unsur "manusia" dalam organisasi dapat memberikan keunggulan bersaing (Syukur, 2012).

Permasalahan yang masih menghadang dan perlu untuk segera diatasi dalam penyelenggaraan pendidikan adalah masih rendahnya kualitas hasil pendidikan di segenap jenjang pendidikan. Tudingan pun diarahkan pada pendidik/guru sebagai penyebab pencapaian hasil pendidikan tersebut, mengingat peran strategis guru sebagai ujung tombak pelaksanaan pembelajaran. Diduga rendahnya pencapaian hasil pendidikan dipengaruhi oleh kinerja pendidik/guru yang rendah. Persoalannya, amat jarang guru yang mampu memotivasi dan mendorong kemampuan internal untuk mengembangkan diri. Sebaliknya guru terjebak pada pola pasif, rutinitas, kurang kreatif, monoton, dan lain sejenisnya.

Kondisi itupun kerap kali distimulir oleh situasi eksternal yang kurang kondusif, yang kurang memberikan rangsangan dan dorongan pada guru untuk mengembangkan kemampuan diri terkait dengan menjalankan tugas utamanya. Bahkan unsur eksternal menjadi faktor penghambat bagi kemunculan kreativitas pengembangan diri guru. Jika disimak, tudingan terhadap guru tidak keseluruhannya benar. Guru bukan merupakan pihak yang mendominasi pembelajaran di sekolah, melainkan perlu ditunjang oleh pihak lainnya, di antaranya adalah kepala sekolah dan pengawas.

Integrated Bisnis Simulator (IBS) merupakan sebuah program komputer terintegrasi yang disusun untuk membuat perencanaan organisasi dengan berbagai kemungkinan perubahan kondisi bisnis yang akan dihadapi, baik kondisi internal maupun eksternal. Perubahan kondisi yang akan dihadapi organisasi tersebut dinyatakan dalam bentuk asumsi-asumsi yang merupakan kuantifikasi dari faktor-faktor yang mempengaruhi organisasi yang dimasukkan (diinputkan) kedalam program. Program yang interaktif ini akan membekali peserta guru - guru SMK di Jakarta dengan pengetahuan di bidang sumber daya manusia. Program simulasi memungkinkan kita untuk mengukur sensitifitas setiap asumsi terhadap target yang ingin dicapai organisasi.

Peran dan fungsi utama dari kedua pihak adalah memberikan bantuan dan bimbingan terhadap guru, terutama terkait dengan pengembangan sumber daya guru terutama yang berhubungan dengan peningkatan kompetensi dan profesionalisme guru. Apabila pengembangan sumber daya guru dapat dilaksanakan secara terencana dan berkesinambungan diharapkan tujuan pendidikan di sekolah dapat tercapai.

Tujuan kegiatan ini adalah untuk mendeskripsikan penerapan manajemen sumber daya manusia guru yang terfokus pada proses pelatihan dan pengembangan sumber daya manusia guru di SMK Jakarta.

\section{METODE}

Dalam kegiatan pengabdian masyarakat terhadap guru - guru di SMK Jakarta tim mengunakan observasi, metode ceramah, diskusi, tanya jawab, pre-post test dan simulasi praktik. Observasi lapangan dilakukan baik sebelum kegiatan dimulai, sedang berlangsung, maupun setelah sebagian kegiatan selesai. Kriteria peserta yang mengikuti kegiatan yaitu guru - guru SMK dijakarta. Total jumlah peserta tiga puluh tiga orang.Selanjutnya, perencanaan kegiatan ini mengacu pada pola manajemen suatu kegiatan. Perencanaan, menurut Suryabrata (2014), adalah pemilihan prosedur, program dan penentuan strategi dan standar yang diperlukan untuk mencapai tujuan. Dalam kegiatan ini perencanaan dilakukan berdasarkan analisis kebutuhan langkah-langkah proses kehumasan yang diawali dengan fact finding (pencarian fakta melalui analisis situasi lingkungan). Setelah didapatkan data, disusunlah agenda kegiatan yang dilakukan oleh tim.

Metode ceramah dan diskusi yang digunakan dikegiatan. Ceramah dilakukan untuk memberikan materi yang didiskusikan serta menginformasikan perubahan teknologi dapat mengembangkan keterampilan, sehingga pekerjaan dapat diselesaikan lebih cepat dan efektif, Peserta dapat meningkatkan semangat kerja seluruh tenaga kerja dalam organisasi dengan komitmen organisasional yang lebih tinggi, Peserta dapat menyiapkan para karyawan yang berkompeten untuk lebih cepat masuk ke tingkat senior (promosi jabatan).

Menurut Suryabrata (2014), metode ceramah adalah sebuah bentuk interaksi melalui penerangan dan penuturan lisan dari pemateri kepada peserta. Ceramah merupakan bentuk cara belajar yang bersifat searah menekankan pada pemberitahuan informasi dari pemateri kepada peserta yang aktif dan pasif. Diskusi merupakan pola tukar pikiran tentang suatu masalah untuk mencapai tujuan melalui analisis, memecahkan 
masalah, menggali, atau memperdebatkan suatu topic antara dua orang atau lebih. Seusai diskusi, peserta diminta untuk latihan membuat absensi, administrasi, system penggajian, BPJS Berbasis Integrated Bisnis Simulator. Setelah melakukan praktek, kegiatan dilanjutkan dengan pengisian kuesioner oleh peserta dan pemberian sertifikat.

\section{HASIL PEMBAHASAN}

Kegiatan pelatihan dan pengembangan sumber daya manusia berbasis integrated bisnis simulator (IBS) Pada Guru SMK di Jakarta dilaksanakan di Sekolah Tinggi Ilmu Ekonomi Indonesia Jakarta. Kegiatan tersebut dibuka tepat jam 07.00 WIB, oleh Drs.Ridwan Maronrong, MSc selaku Ketua Sekolah Tinggi Ilmu Ekonomi Indonesia Jakarta STEI dan Hartono Hutomo,S.TP selaku Direktur Hebat Inovasi Indonesia. Kegiatan ini dihadiri 33 peserta dari SMKN Di Jakarta.
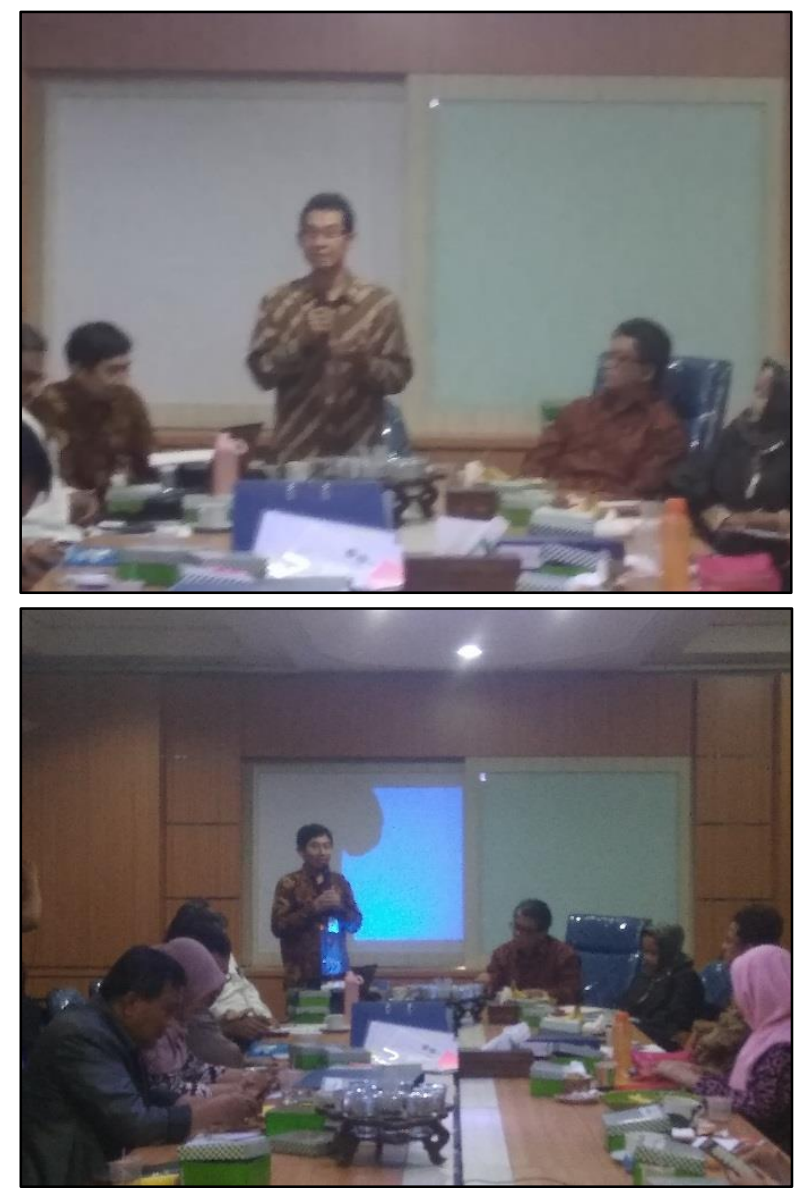

Gambar 1. Pelatihan dan Pengembangan Sumber

Daya Manusia Berbasis Integrated Bisnis

Simulator (IBS) pada Guru SMK Di Jakarta

Dilaksanakan di Sekolah Tinggi Ilmu Ekonomi

Indonesia Jakarta

Pada sesi pertama peserta diberikan Pelatihan membuat absensi karyawan berbasis integrated bisnis simulator (IBS) Dipandu Bpk Hartono Hutomo,S.TP didampingi trainer dan Central Office. Pelatihan ini bertujuan untuk melatih karyawan untuk datang on time, Data absensi tersimpan dan tersusun dengan rapi sehingga mudah bagi HRD untuk mengaksesnya, Mudah membuat laporan absensi karyawan karena datanya sudah tersusun rapi. Data tidak bisa dimanipulasi dan absensi tidak bisa dititip ke orang lain.
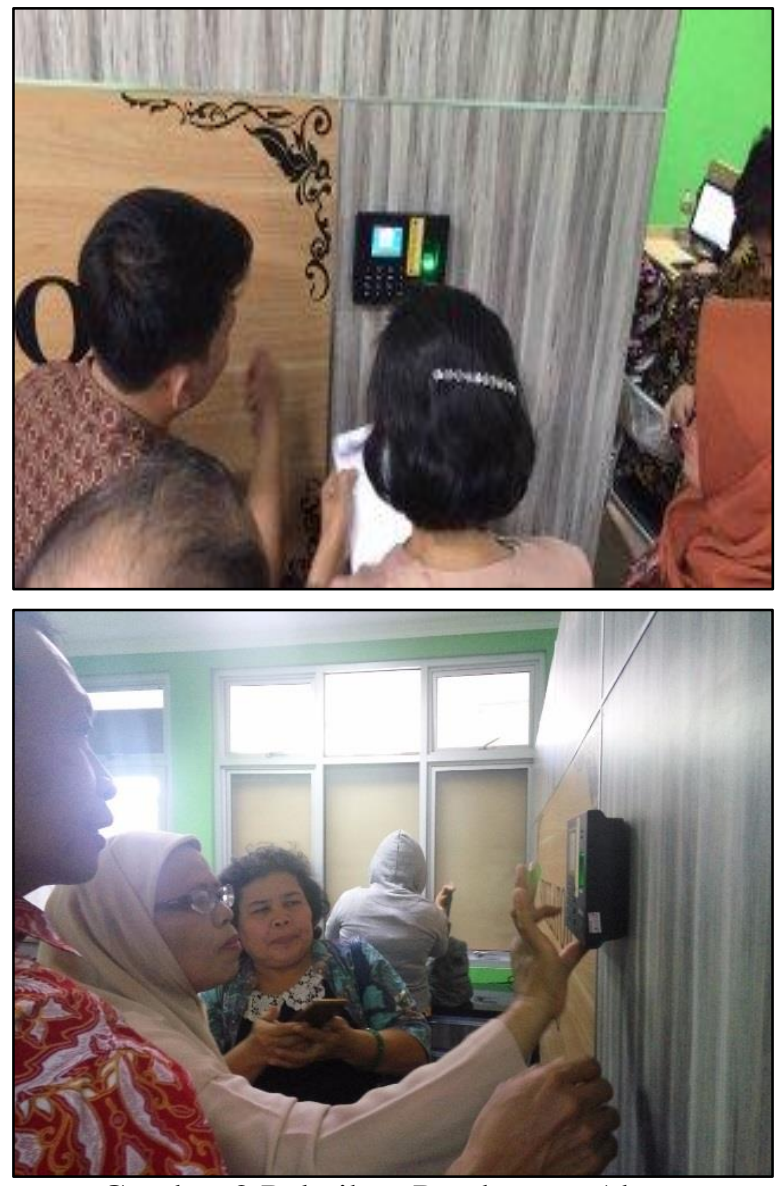

Gambar 2.Pelatihan Pembuatan Absen

Elektronik

Pada sesi kedua peserta diberikan pelatihan membuat administrasi karyawan berbasis integrated bisnis simulator (IBS). Guru - guru SMK Diajarkan penangan dokumen administrasi karyawan, pemeliharaan dokumen administrasi karyawan. Pada sesi ketiga diberikan pelatihan membuat sistem penggajian. Guru - guru SMK diberikan pelatihan untuk mengerti cara pembuatan daftar gaji dan upah. Data yang dipakai sebagai dasar adalah SK pengangkatan karyawan baru, kenaikan pangkat, perubahan tarif, penurunan pangkat, pemberhentian sementara dari pekerjaan, dan daftar gaiji bulan sebelumnya dan daftar hadir. Biaya tenaga kerja didistribusikan kepada departemen-departemen 
yang menikmati manfaat tenaga kerja.

Pada sesi keempat diberikan pelatihan membuat BPJS kesehatan dan Ketenaga kerjaan karyawan. Program jaminan sosial merupakan program perlindungan yang bersifat dasar bagi tenaga kerja yang bertujuan untuk menjamin adanya keamanan dan kepastian terhadap setiap risiko sosial ekonomi. Kepesertaan bersifat wajib dalam Program JHT dan sesuai dengan tahapan kepesertaan, dimana Kepesertaan Penerima Upah selain penyelenggara negara diantaranya terdiri dari semua pekerja yang bekerja pada pada perusahaan dan perseorangan serta WNA yang telah bekerja di Indonesia lebih dari 6 bulan. Sedangkan Kepesertaan Bukan Penerima Upah terdiri dari para pemberi kerja dan pekerja di luar hubungan kerja/mandiri. Manfaat JHT adalah berupa uang tunai yang besarnya merupakan nilai akumulasi iuran ditambah hasil pengembangannya, yang dibayarkan secara sekaligus apabila peserta Program JHT mencapai usia 56 tahun atau meninggal dunia atau mengalami cacat total tetap.

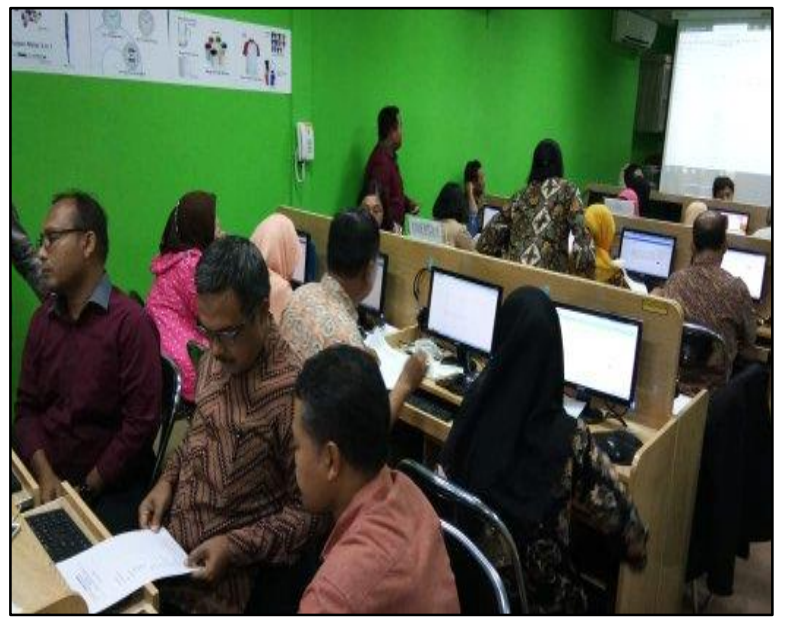

Gambar 3. Pelatihan Pembuatan Administrasi Karyawan Berbasis IBS

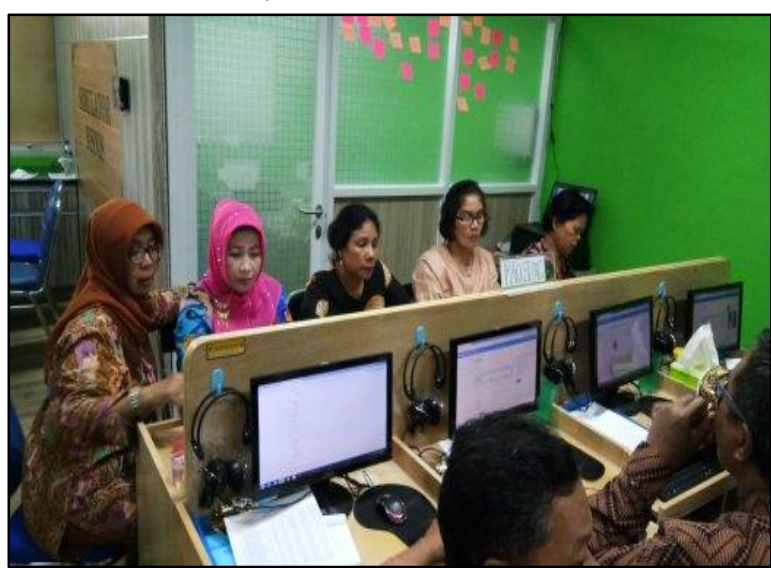

Gambar 4. Pelatihan Pembuatan Administrasi Penggajian Berbasis IBS
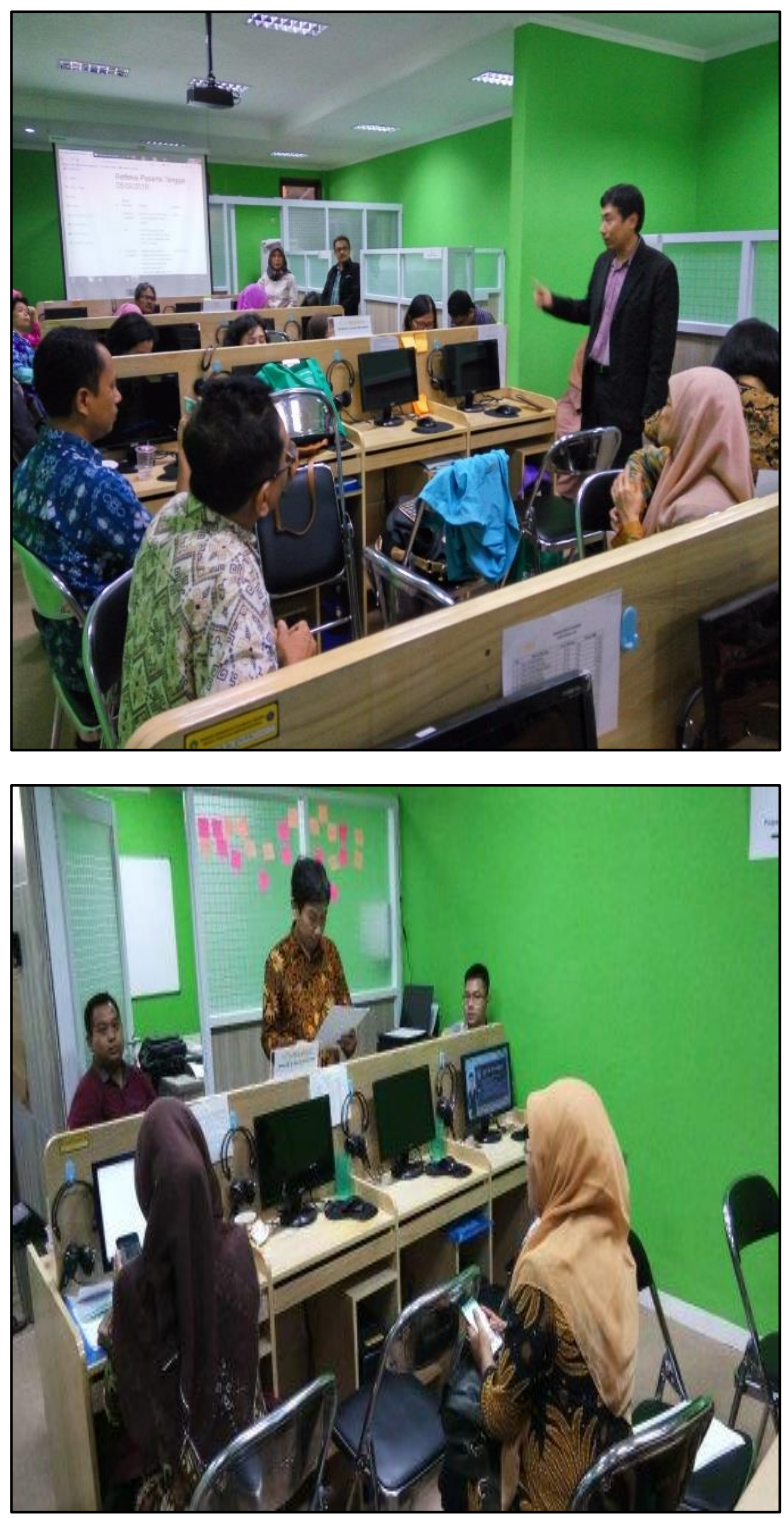

Gambar 5. Pelatihan Membuat BPJS Kesehatan dan Ketenagakerjaan Karyawan Berbasis IBS

Secara umum, seluruh peserta pelatihan dan pengembangan sumber daya manusia berbasis integrated bisnis simulator (IBS), menyatakan bahwa kegiatan pelatihan dan pengembangan sumber daya manusia berbasis integrated bisnis simulator (IBS) untuk Guru SMK di Jakarta, sesuai dengan kebutuhan mereka dan materi yang disampaikan mudah untuk dipahami, serta mereka akan menceritakan kegiatan tersebut ke orang-orang di sekitar. Namun, ada 4 peserta yang menyatakan penyuluhan tersebut belum memotivasi untuk meningkatkan pelatihan dan pengembangan sumber daya manusia berbasis integrated bisnis simulator (IBS) pada Guru SMK di Jakarta dan 3 orang belum tahu kapan akan mengembangan sumber daya manusia berbasis Integrated Bisnis Simulator (IBS). 


\section{KESIMPULAN}

Kegiatan yang dilaksanakan di ruang simulator bisnis STIE Indonesia berjalan dengan baik dan lancar, dengan harapan yaitu guru guru SMK Jakarta dapat menerapkan materi yang telah disampaikan dengan menigkatkan kinerja SDM dalam mengajar misalnya dalam pembuatan perangkat pembelajaran yang akan berdampak pula pada peningkatan prestasi belajar siswa. Saran yang bisa diberikan adalah diharapkan kepada guru guru SMK di Jakarta untuk meningkatkan wawasan pengetahuan serta ketrampilan kinerja SDM guru - guru SMK. Selain itu, diharapkan agar guru SMK di Jakarta dapat mempertahankan pencapaian kinerjanya sehingga proses pembelajaran dapat berjalan sebagaimana mestinya.

\section{DAFTAR PUSTAKA}

Mangkunegara, A.P. 2013. Manajemen Sumber Daya Manusia Perusahaan. PT Remaja Rosdakarya. Bandung
Sahertian, P.A. 2008. Konsep Dasar dan Teknik Supervisi Pendidikan Dalam Rangka Pengembangan Sumber Daya Manusia. Rineka Cipta. Jakarta.

Suryosubroto, B. 2010. Manajemen Pendidikan di Sekolah. Rineka Cipta. Jakarta.

Syukur, F. 2012. Manajemen Sumber Daya Manusia Pendidikan. PT Pustaka Rizki Putra. Semarang.

Widodo, S. E. 2015. Manajemen Pengembangan Sumber Daya Manusia. Pusaka Pelajar. 